\title{
Metacognitive, cognitive and affective aspects of learning styles and strategies: A phenomenographic analysis
}

\author{
J.D. VERMUNT \\ Leiden University, ICLON-Graduate School of Education, P.O. Box 9555, NL-2300 RB \\ Leiden, The Netherlands
}

\begin{abstract}
This paper addresses the following questions: how do students perform metacognitive, cognitive and affective learning functions; how is the execution of learning functions regulated by internal and external sources; what learning styles can be discerned from the viewpoint of learning functions and regulation? Subjects were students from an open distance university and a regular university. They were interviewed extensively about their learning strategies, mental models of learning, learning orientations and interpretations and appraisals of instructional measures. The interviews were analyzed in a phenomenographic way. The results indicate that there are large differences among students in the manner in which they carry out learning functions, that these differences are associated with internal and external sources, and that four qualitatively different learning styles can be discemed: an undirected, a reproduction directed, a meaning directed and an application directed learning style. Mental models of learning and learning orientations turn out to be related to the way in which students interpret, appraise and use instructional measures to regulate their learning activities. It is concluded that in many instances instructional measures do not have the intended effects. Suggestions are given regarding the implications of these results for the improvement of teaching practices in higher education.
\end{abstract}

\section{Introduction}

Instruction does not lead to learning automatically. The learning activities that students employ determine to a large extent the quality of the learning outcomes they achieve. Therefore, teaching should be directed at encouraging students to use high-quality learning activities. In this article, research on the learning activities of students will be reported. Learning activities are viewed here as thinking activities that people employ to learn, learning strategies as particular, often used combinations of learning activities. Learning styles are conceived here as relatively stable, but not unchangeable, ways in which students learn. The majority of study strategies research in higher education has focused on cognitive processing strategies and motivation (e.g. Schmeck, 1983; Entwistle \& Ramsden, 1983). Recently, in research on learning processes of secondary school students, attention has been drawn to the importance of metacognition (e.g. Brown, 1987). Metacognition refers to learners' views and beliefs about learning and to the active regulation of their 
Table 1. Learning activities: types and categories

\begin{tabular}{ll}
\hline Types & Categories \\
\hline Cognitive & $\begin{array}{l}\text { Relating, structuring, analyzing, concretizing, applying, } \\
\text { memorizing, critical processing, selecting. }\end{array}$ \\
Affective & $\begin{array}{l}\text { Attributing, motivating, concentrating, judging oneself, } \\
\text { appraising, exerting effort, generating emotions, expecting. }\end{array}$ \\
Regulative & $\begin{array}{l}\text { Orienting, planning, monitoring, testing, diagnosing, } \\
\text { adjusting, evaluating, reflecting. }\end{array}$ \\
\hline
\end{tabular}

learning processes (Flavell, 1987). The focus here is on metacognitive aspects of student learning in higher education: regulation strategies and mental models of learning. An attempt will be made to link these metacognitive aspects to students' cognitive processing strategies and to their study motivation, with the aim of enriching and broadening earlier conceptualisations of students' learning styles and strategies in higher education.

In general, three types of learning activities are discerned: cognitive, affective and metacognitive or regulative (e.g. Short \& Weisberg-Benchell, 1989). A study of the literature indicated that these learning activities may be grouped into the categories depicted in Table 1 (Vermunt, 1989; 1992). Cognitive processing activities are those thinking activities that people use to process learning content. They lead directly to learning results in terms of knowledge, understanding, skill and so on. Examples are: looking for relations among parts of the subject matter (relating), distinguishing main and minor points (selecting), thinking of examples (concretizing) and looking for applications (applying). Affective learning activities are directed at coping with the feelings that arise during learning, and lead to an emotional state that may positively, neutrally or negatively affect the progression of a learning process. Examples are motivating oneself, attributing learning results to causal factors, attaching subjective appraisals to learning tasks and getting blocking emotions under control. Metacognitive regulation activities are directed at regulating the cognitive and affective learning activities and therefore indirectly lead to learning results. Examples are: orienting on a learning task, monitoring whether the learning process proceeds as planned, diagnosing the cause of difficulties and adjusting learning processes when needed.

In considering these activities, it is striking to observe that these are thinking activities that people not only need to learn, but also need to do their job. In functional descriptions these terms are often used: somebody with analytic skills, someone who knows how to readily discern relevant from irrelevant 
information, has the capability to make knowledge usable, can motivate oneself and others, can independently plan and monitor work activities, and so on. In reading personnel advertisements in newspapers it is remarkable that for many senior jobs, it is seemingly ever less important what academic subject someone has qualified in (e.g. 'an academic education'), if only the candidate has these thinking skills. In modern times, and in face of the increasing redundancy of knowledge, it is also less important which specific domain knowledge someone has acquired. It is obviously more important that people acquire skill in thinking activities that make them capable of assimilating new knowledge in order to deal with the huge amounts of information that they are confronted with in their work. The societal demand on higher education to pay more attention to 'teaching how to learn and think independently' is increasing.

Another striking attribute of the categories of learning activities described in Table 1 is that they can also be related to instructional activities. What teachers do to teach people something can be described in the same terms; they explain the relations among learning content, provide examples, show how a theory may be applied in practice, motivate students, and plan, monitor and evaluate the learning processes of students. It seems that learning and instructional activities can be seen as images of each other and that they may be described in similar terms. Thus, one can speak of learning functions; functions that have to be fulfilled for worthwhile learning processes to be realized (compare Shuell, 1988). Who fulfils these functions, the learner or the teacher, may vary, if only they are fulfilled. When some functions are not fulfilled one may speak of incomplete learning processes, which is often the case.

From the viewpoint of the influence of instructional activities on students' use of learning activities, three basic instructional strategies can be discerned: taking over, or substituting, learning and thinking activities from students (strong external control); activating students to use certain learning and thinking activities (shared control); and capitalizing on the proper use of learning and thinking activities that students already possess (loose external control). In the first case the teacher, for example, explains all relations between two theories, in the second case instruction stimulates students to search for relations between the theories. In the third case the teacher pays no attention to the relations between the theories, and he or she expects from the students that they will search and find those relations themselves.

The question now arises as to whether certain psychological laws may be discovered in the way that people utilize various learning activities. Is the employment of some learning activities associated with the use of others? 
Can learning strategies be identified, consisting of typical combinations of thinking activities? These are central questions in the study reported here.

As stated above, active 'on-line' regulation of learning is one aspect of metacognition; it is the more dynamic aspect. Another aspect is more static in nature; the knowledge, beliefs, conceptions and views people have about learning processes, the functioning of one's own thinking and the variables that influence these processes. In the first years of metacognitive research many studies were based on a presumption of knowledge related to specific facts people have about learning, such as the duration and capacity of shortterm memory. More recently the total, coherent system of conceptions of learning and associated phenomena are more in focus; the mental models of learning that people possess. These learning conceptions refer to, for example, conceptions of learning and thinking activities, conceptions of oneself as a learner, conceptions of learning objectives and learning tasks, conceptions of learning and studying in general and regulation conceptions: views on the task division between oneself and others in learning processes (e.g. Volet, 1990; Marton, Dall'Alba and Beaty, 1993; Prosser, Trigwell and Taylor, 1994).

Aspects of student learning that are well researched are study motivation (Entwistle \& Ramsden, 1983) and learning orientations (Gibbs, Morgan \& Taylor, 1984). Learning orientations refer to the whole domain of personal goals, intentions, attitudes, worries and doubts of students in relation to their studies. They are supposed to influence learning because students, within the repertoire of learning activities they master, mainly use those activities they think are best suited to realize their personal goals.

Little is, however, known about the interplay between self-regulation and external regulation of learning. This, for example, refers to the way in which students interpret, appraise and use external regulation devices (didactic measures), dependent on their mental models of learning, learning orientations and skills in learning. It is often supposed that didactic measures like learning objectives, assignments, self-tests, directions for studying, and so on, are desirable devices for the improvement of student learning. The regulation power of these types of teaching devices, especially in instructional design theories, is presumed, but rarely empirically studied. The actual influence of these external regulation devices on students' use of study strategies, and how this influence is mediated by students' mental learning models and learning orientations, remains unclear.

What has also remained unclear until now are the interrelations among students' processing strategies, regulation strategies, mental learning models and learning orientations. These interrelations are referred to here in terms of the concept of 'learning style'. The term 'learning style' is usually used in a narrower sense, for example, in the sense of the learning activities 
students usually employ to learn (e.g. Moran, 1991). Here the concept is used in a broader sense, and also includes students' mental models of learning and learning orientations. 'Learning style' means here a coherent whole of learning activities that students usually employ, their learning orientation and their mental model of learning; a whole that is characteristic of them at a certain period. Within this broader meaning learning style is thus a coordinating concept, in which the interrelations among cognitive, affective and regulative learning activities, mental models of learning and learning orientations are united. Learning style is not conceived of as an unchangeable personality attribute, but as the result of the temporal interplay between personal and contextual influences.

From the above it is clear that learning functions play a central role in the theory on regulation of learning processes (Vermunt, 1989, 1992). However, little is known about the manner in which students carry out these functions in a real educational context, and about the way in which this execution is regulated by internal and external sources. Insight into these processes can make an important contribution to the improvement of instructional practice in higher education because, in line with the foregoing argument, the learning and thinking activities of students should be taken as a starting point in designing instruction.

Research questions. The purpose of the studies reported in this article is principally to get more insight into the way in which students carry out the various learning functions that are related to their learning styles on the one hand, and the external regulation imposed by instructional activities on the other. The focus here is on small scale, but in depth, interview studies and two of these studies are reported here; one involving open university students and one involving regular university students. More specifically, the following research questions were formulated:

1. In what ways do students carry out the various learning functions in their normal studies?

2. How is this execution internally and externally regulated?

3. What learning styles can be identified from the perspective of the first two questions?

Research contexts. Studying at the open university means that students work a lot with self-instructional materials. Beside their actual learning content, these materials contain a lot of in-text teaching devices meant to support and direct the learning processes of students. Examples are: introductions, highlighted central concepts, summaries, overviews, rehearsal units, assignments, learning objectives, questions, tasks, directions for studying, and self-tests with feedback. Students can also attend a limited number of meetings guided by a tutor. In contrast, studying at the regular university is characterised by 
a combination of independent study, lectures, and tutorials. Students study independently the study materials chosen or compiled by their teachers. These study materials may also contain regulation devices like objectives, questions, and the like, but most of them do not. There are relatively many contact periods with teachers that students may attend. In these lectures and tutorials teachers clarify the subject matter and provide students with directions for their independent study.

Research methodology. The resultant interview data were analyzed from the theoretical perspective outlined above. The phenomenographic research methodology was used for these analyses. Phenomenography is a research methodology to map the qualitative different ways people experience, conceptualize, perceive and understand phenomena (Marton, 1986). Objective of the method is to frame and describe these qualitative differences in conceptual categories (Säljö, 1988). The phenomenographic approach has been used in various educational research contexts and with various populations. Marton et al. (1993), for example, analyzed interviews with British Open university students in a phenomenographic way to describe differences and developments in learning conceptions of students. Pramling (1990) has analyzed interviews with Swedish preschool children about their learning conceptions phenomenographically. Murphy (1990) has, in a similar way, analyzed her interview data of adult students in Turkish open distance education. Prosser et al. (1994) used the phenomenographic method in a study on conceptions of teaching and learning of Australian university teachers. The 'phenomenon' dealt with in this article is 'studying in the beginning phase of higher education'. For a more elaborate discussion of the phenomenographic research methodology the reader is referred to Marton $(1986,1990)$ and Säljö (1988).

\section{Method}

Students. (1) The OU-Study. A sample of 34 first year OU-students was taken from three different types of subject areas: students from the Cultural Sciences Orientation Course, from the Foundation Law Course and students who did a more exact course: either the Natural Sciences Orientation Course or the Systems and their Regulation Course from the Technical Sciences subject area. Half the sample consisted of women, the other half of men. Of the 34 students, $25(74 \%)$ were willing to participate in the study. Due to a technical malfunction one interview was not recorded on tape. The residual group of respondents consisted of four men and one woman from the Law Sciences, five men and five women from the Cultural Sciences and four men and five 
women from the Natural and Technical Sciences. The mean age of these 24 students was 33.0 years.

(2) The RU-Study. A sample of 20 first year Psychology students was taken from a regular university. Corresponding to the population distribution, 14 full time and 6 part time students were selected. These 20 students were approached in writing with the request to participate in an interview, and 11 of them (55\%) agreed to do so. This response group consisted of eight full time and three part time students, nine women and two men, and the mean age was 22.4 years.

Interview schedules. In both studies similar interview schedules were used. These schedules contained some open core questions and a number of suggestions for continuation questions. Questions were asked about, among other things, the manner in which students studied the course materials, the role of tutorials and fellow students in their studies, views on studying at the university, study expectations and study plans. In the RU-schedule also questions were asked about the role of lectures in the studies.

Procedures. (1) The OU-Study. Students who had declared, in a telephone call, their willingness to participate in the study, were interviewed by one interviewer, almost always at the student's home. All interviews were divided among three interviewers and progressed in a semi-structured way. Students were stimulated to explain and clarify everything related to their style of learning. In all but one cases permission was granted to tape-record the interview. Elaborate notes were taken in the exceptional case. Each interview lasted approximately 50 minutes. Participation in the study was voluntary and as the only reward the respondents were promised a short report of the study after its completion.

(2) The RU-Study. Students in this study volunteered to participate via a postal response to a written invitation. Failure to respond resulted in a followup reminder. The remainder of the procedures followed differed from those of the OU-study only insofar as interviews were conducted on university premises, lasted approximately an hour and were rewarded with ten guilders. All interviews were tape-recorded.

Data analysis. All interviews were transcribed and printed, resulting in 450 pages of transcript. The transcripts were then analyzed phenomenographically. As a first step all interviews were read completely. Subsequently, the interviews were studied several more times, during which phase quotes were selected that were relevant to the research questions. These quotes were organized on a word processor, per individual, under one of the five central interview topics: cognitive processing, regulation of learning, affective processes, mental models of learning and learning orientations. These selected quotes were subsequently printed and formed the basis of the subsequent 
iterative data analysis. Selected quotes were studied per topic. Characteristic aspects of the learning styles of the students were recorded as features in a list, that distinguished between several thematic aspects. These features were subsequently grouped and regrouped into categories, based on similarities and differences. These categories were then described, and the descriptions were compared with the original data. Based on these comparisons, collections of features were regrouped, and so on. After reaching a stable grouping in the categorical system, ultimate descriptional categories were formulated that represented the most essential features of the groupings that were found. Finally, each category was illustrated with typical quotations.

\section{Results}

The above described method of analysis resulted in four main categories of description, which represent qualitatively different styles of learning. These styles differ from each other in five areas: the way in which students cognitively process learning contents, the way in which students regulate their learning, the affective processes that occur during studying, the mental learning models and the learning orientations of students. These learning styles will be described here along these themes. They may be named as an undirected, a reproduction directed, a meaning directed and an application directed learning style. These four learning styles are prototypical styles, in the sense that a student can manifest features of different styles. All 35 students however show a dominant style. For six students this is the undirected learning style, for twelve the reproduction directed style, for ten the meaning directed style and for seven the application directed style.

The descriptions will be illustrated by characteristic examples of quotes of students. The student number is indicated between brackets behind quotations, together with the university and subject area to which the student belongs. OU refers to Open University, RU to Regular University. LS stands for Law Sciences, CS for Cultural Sciences, TS for Technical Sciences, NS for Natural Sciences, and PS for Psychological Sciences. In the quotes 'I' means Interviewer and ' $S$ ' means Student.

\section{Undirected learning style}

Cognitive processing. Students with this learning style have a lot of trouble performing almost all learning functions. They have much difficulty in selecting the most important parts in the study materials and in distinguishing between main and minor points. They find everything of equal importance and pay equal attention to all parts of the learning contents. They do not 
know what they have to remember, and the study materials are too voluminous to remember everything. Because these students are not able to discern levels of importance in the subject matter, they hardly get around to a further processing of the study materials. Their most important processing activities are reading and rereading the study materials many times. They have trouble seeing relations between the parts of the subject matter and structuring these parts in bigger wholes. They also have difficulties with concretizing and applying the subject matter and they see little relations between what they study and phenomena in daily life.

S: "It is very difficult to select. When you are in an ordinary class you ask: "do you have to know this or is this not so important?'. But when you are on your own that is very difficult. You never know well what they want you to know."

I: "Do the learning objectives indicate what is important?"

S: "Yes, but these are also very general. That you can explain something in broad outlines, for example, how the earth is built up. But then you still do not know how much they want you to know about that. No example is given about how much you should know about it. I don't find them so clear. (...) Some people know it as soon as they have read it, but that is not the case with me. I really have to write down everything, if necessary three times. Before the exam I just will write down everything another time. That is the way it really goes in. (...) I cannot learn in another way." (17, OU, NS)

Regulation of learning. Typical of this learning style is that students strongly direct themselves toward the regulation as supplied by instruction, but they experience insufficient hold on that. They experience a lack of regulation in their learning activities. Students find the objectives, instructions and introductions given by the teacher or the book too general and not clear enough to support the regulation of their learning. Often they also experience tensions between questions and assignments that are aimed at the broad outline, and which distract them from the factual information to which they themselves are directed. The only variations in their approach to studying are of a quantitative nature: the more difficult a chapter or learning unit is, the more time they spend on it by rereading it more times.

In this learning style monitoring processes consist mainly of becoming aware of the difficulties students themselves experience with the regulation of their learning processes. For example, they notice that they do not have a feeling for what is important, that the quantity of the study materials is far too large to process in a reasonable time, and that their pace of studying is too slow. These students also experience problems testing and evaluating their learning results. They are strongly focused on the questions, assignments, and self-tests supplied in the course materials or by teachers, but what they need to know for the exam remains unclear to them. Their only adjustment strategy 
when they do not understand something is to stay reading and rereading the difficult parts.

S: "Regularly there is written: 'you may read this, but you do not have to learn it by heart.' For example, a number of historical dates are given, that I find worthwhile to know, but then there is written: 'you do not have to remember them'. (...) Well, if I do not have to learn everything there is in the book. There is quite a lot in it, I think, in the sense of 'oh, just read it, it is not so important, it is nice to know, but...'. I do not know if that is always so good. Maybe certain facts are good to have in your mind. (...) There are questions that instruct you to make certain connections, or to find out contradictions between John's and Peter's story, but evidently I do that too little" ( $8, \mathrm{OU}, \mathrm{CS})$

These students indicate that they study in a manner that they have always done. OU-students often revert to their experiences of many years ago in secondary education for their current approach to studying. In secondary education this way of studying worked well for them, but the increase in the quantity of study materials brings them into problems now. They realise that their current learning style does not suffice any more, but they do not know how to approach their studies in a better way.

Affective processes. Students with this learning style are afraid that they are not able to cope with their studies, that they do not deal with them well, and that they can not learn the study materials. They have a negative view of themselves as students, and have little confidence in their study capabilities. They are disappointed in themselves and have built up failure expectations in the course of their studies. They worry about their own achievements and begin to postpone studying.

I: "Are there things you have worried about with regard to your studies?"

S: "Yes, my own achievements. I had expected that these studies would not be easy, but I had not expected that they would be so hard. I worried a lot about that, and I still do. When I have to study something I keep thinking again and again: why am I not able to do it? I always could. I just fail now." (33, RU, PS)

Mental models of learning. These students see almost all cognitive and regulative learning functions as tasks of instruction. Without exception they say to want a lot of external regulation, more than they are getting now, and they want it in terms of the substitution of thinking activities they have to employ currently. With regard to cognitive learning functions, students with this learning style are, for example, of the opinion that the teachers or course writers should explain the subject matter very clearly, sum up what students need and need not to know, show very clearly the relations between the different topics covered, and sketch an overview of the learning contents. The regulation functions they expect of the course materials or teachers are, among other things: explain how they should study, give assignments 
to do at home, explicate difficult parts until students understand them, and check whether students study and master the subject matter. They also want many assignments, self-tests and trial exams. Students also find that tutors or teachers should regulate their learning more than they do in practice.

I: "What do you find the task of a teacher in good education?"

S: "That he explains clearly. That he also gives assignments that you can make at home, so that you can study the subject matter in a stepwise manner. And that he tests whether the students also study and master the subject matter. I do not mean the big exam, but I am used to get homework assignments, for example. (...) I find tutorials important because there I can ask questions more directly than in lectures. If you cannot understand something, you can ask, ask, ask until you do understand it." (33, RU, PS)

Cooperation with fellow students is considered very important by students with this learning style. Affective functions that students attach to this cooperation are, for example, getting support from others, motivating each other to go on at weak moments, and noticing that other students have the same problems and questions. They also find it important to consult other students when they do not understand something. As most important tasks for themselves these students see taking the time to study, studying regularly and getting the subject matter into their heads.

Learning orientations. Students with this learning style have started their studies with a variety of learning orientations. Their experiences with studying until now have however raised doubt about the realizability of their long-term goals. Typically, there is a somewhat ambivalent, insecure attitude towards their studies. They ask themselves, for example, whether they have chosen the right course, studies or subject area, and whether they are able to cope with their studies. They doubt their own capabilities to succeed and do not know whether they will go on.

S: "In the beginning the spirit was very high, but that has become less. (...) It is a question whether I will go on. Maybe, if I would pass the exam of this first course, the spirit becomes higher, but I do not see that happen yet. I want to look at it per course and if it satisfies or if I can cope with it, I say: I go on with it." (8, OU, CS)

\section{Reproduction directed learning style}

Cognitive processing. Students with this learning style spend a lot of time selecting what are, in their view, the most important parts of the study materials. They underline or mark in their study texts the parts they have to know by heart for the examination. In order to distinguish between main and minor points they focus on the indications given by course writers, authors of study books, tutors or teachers. These indications supply them with enough clarity 
as to what the important parts are and, in general, they have little trouble with the process of selection. Often quantitative criteria are decisive for the importance they attach to parts of the subject matter, such as the number of pages spent on a topic, the number of times certain subjects are repeated in a text, and the amount of time teachers spend on a topic. Besides the selection of main points in study materials, memorizing and rehearsal form the most important processing activities within this learning style. Typical is that the study materials are processed in a stepwise fashion, sequentially and thoroughly. Students work through the study materials page by page, part by part and study every topic separately.

S: "There are no parts of which I think: Oh, I know those already. There are parts that look familiar to me, but for me that is no reason to say: I just do that a bit faster, because I know that. No, I read everything very precisely! (...) Then I read it all over again. The second time I not only read, but I also mark. With a marker pen I indicate what text I should definitely know by heart. Between 40 and $50 \%$ is yellow then, so very much. And central concepts and words I should have in my head I mark red. When the exams are coming closer, I start reading everything for the third time. (...) In my view there is only one way: I have to make sure that a mass of those concepts gets into my brains. So it is: rehears, rehears, rehears. If I do it four times I know it better than after three times, and after five times I know it better than after four times." (23, OU, CS)

Regulation of learning. Students with this learning style are very sensitive to indications about what course parts teachers or course writers consider most important. They restrict themselves to the examined subject matter and consult no other sources about the course contents. Mostly this reproductive learning style is regulated externally: students let themselves be directed by the regulation sources supplied by instruction, such as introductions, learning objectives, directions for studying, questions, assignments and self-tests. Students test and evaluate their learning results mainly by doing the questions, tasks and tests supplied by instruction. Often however this happens in a somewhat superficial way. Students think, for example, for a moment whether they would be able to answer the questions, without actually doing so. Also they look whether they understand the questions and if that is the case, they think they master the subject matter enough.

S: "I appreciate those self-tests. They make you know where you have to go to. You know exactly what they consider to be the main points and you know of certain other things that they probably do not find them so important. So, I do not have to study these so intensively. (...) Sometimes there is something written like: 'you are not expected to learn by heart the part that follows now, only the main points.' Then you get the text and the most important points are often immediately asked for, like 'name the three points that Brown has 
mentioned in the text regarding ...' That they find the most important and the remainder of Brown's text you may forget, I assume. Only those things they consider important and only those you have to remember." (22, OU, CS)

The only variations in their approach to studying are quantitative in nature. Sometimes it costs them more time to remember the course content and they have to rehearse it more often. Variations in their approach to different courses mainly have to do with what they memorize. If they think that the exam will be fact-oriented, they learn details, names and concepts by heart. In other courses, they learn broad outlines, comparisons and summaries by heart. Monitoring processes are, within this learning style, mainly directed at the pace of studying. Often these students indicate a need for a lot of time to study. The most chosen adjustment strategy when encountering difficult parts is more often rereading and rehearsing them. These students seldom diagnose the cause of their difficulties or reflect on their approach to studying. Mostly, their way of studying is not very different from their approach in secondary education.

Affective processes. Students with this learning style mostly put a lot of effort and time into their studies. They are often insecure about what will be asked at the examination. They are afraid that they have to know everything and that they will forget something. Sometimes this leads to excessive underlining, marking or very extensive summaries. Their personal interests play only a small role in the regulation of their learning. Subject matter that interests them is remembered faster than subject matter that they do not find so interesting.

S: When I read I underline almost everything, because I don't like the idea of forgetting something when I start learning it. (...) But when I learn it, I underline the real essential parts a little bit thicker. When I start rehearsing, then I only look at the thickest lines. But I experience that as a negative point, because in fact I should select from the start. That would save time. But then I have the feeling: I may have selected now, but possibly I forgot something important. That is maybe an insecurity in my study method." (34, RU, PS)

Mental models of learning. The most important study goal for these students is to pass examinations. By 'studying' they mean absorbing the offered knowledge for the examination. Their regulation conception indicates a strong preference for instructional strategies that substitute for their own learning activities. Regarding the cognitive learning functions, these students appreciate it when the most important parts of the subject matter are clearly indicated. They also feel that the subject matter should be well segmented, and should be repeated regularly, in another context. They expect the course materials to show the relations between the different chapters or learning units and desire a clear structure for the study materials. They consider discussions 
among students about study topics as useless. As the tasks of teachers these students see mainly the clarification and extra explanation of subject matter. In their opinion, teachers should give extra examples and stress those topics they consider important. They should indicate the relations between parts of the subject matter, give an overview of what is in the book, and explain the structure of the subject matter clearly. As tasks of instruction in the affective area these students see, among other things, making students enthusiastic about the subject matter and generating interest in it. The regulative tasks they think teachers have are, for example, telling exactly what they expect from students in examinations, asking questions to check students' understanding and making clear to students what has not been understood.

\section{I: "What do you consider good education?}

S: "Good education is mainly clear education, showing unambiguously what they mean, and also telling what they want from you at the exam. You must know what you are up to, that you know what you have to do and how you can pass the exam. That I consider good education, that you know what is expected from you. (...) Learning is just being able to reproduce what you have learned." (34, RU, PS)

Students with this learning style see the intake of knowledge of the subject matter into their head in order to make it reproducible as their central task in studying. The value of learning activities is judged in terms of their contribution to a better remembering of the subject matter. Learning by heart and rehearsing the subject matter many times are considered the most important learning activities by these students. Critical processing is not considered a relevant learning activity, because they think the authors know it much better than a beginning student anyway.

Learning orientations. A learning orientation aimed at testing one's own capabilities, coupled with a strong directedness at passing the examinations, is often characteristic for this learning style. Students want to know whether the studies are feasible for them and whether they can cope with higher education. Passing examinations is the main objective for these students, because that is a proof that they can cope with their studies, and because then they know whether they have taken in the knowledge they have absorbed well. They want to score as high as possible for the examination. The main objective of their studies is in acquiring study points and obtaining certificates.

S: "My expectation at the beginning was: would it be difficult? Would I be able to cope with academic education? (...) I don't have a need for discussions in tutorials, for the time being I restrict myself to the subject matter. And I will need my hands and feet to get it into my head in such a way that I can cope with academic education. (...) You have to get a sufficient grade to be able to go on, 
so with sweat in my hands I made the final self-test in the last course unit. (23, $\mathrm{OU}, \mathrm{CS})$

\section{Meaning directed learning style}

Cognitive processing. Characteristic of the manner in which main points are selected within this learning style is the larger role of intrinsic interest in the subject. Students primarily try to get parts out of the study texts, lectures or tutorials that they themselves find important. They try to understand the meaning of a story, and they have little attention for details. What they find important are main lines, central concepts, the essence of the material, hypotheses, theories that try to prove or disprove those hypotheses, the evidence that is provided, and how one constructs theories. Typical of this learning style is that students often try to interrelate parts of the subject matter. They search, for example, for analogies between formulas, think about relations between different topics within a learning unit or chapter, between different learning units or chapters and between different study books. They also look whether they can build relations to knowledge they already have about the domain. Students with this learning style try to build a total picture of the subject matter. Often they write down the main line of a learning unit or chapter in a strongly abbreviated or schematical way, for example, in the form of key concepts with arrows that symbolize the mutual relations. These students also often try to approach the subject matter in a critical manner, by asking questions about it, and by forming own interpretations, opinions and conclusions.

S: "My way of studying is that I always try to see relationships and to get an overview over the subject matter. There is a certain line in a chapter, a story, and I try to follow that. For example, there are different theories about a topic. Then I summarize the core of each theory and also the pro's and contra's, and which theory is a reaction to which theory. (...) My summary is very important to me, because I get an overview over the subject matter, I see the main lines and connections that get lost when I only read from page to page." (31, RU, PS)

Regulation of learning. In most cases this learning style is regulated internally: the selecting, relating, structuring and critical processing activities are activated by the students themselves. For example, they let themselves be guided by questions that they ask during studying and they try to find answers. Students with this learning style also consult non-prescribed literature related to the course topics, to deepen their interests, to better understand the subject matter or to get a broader view on it. These students adapt their approach to studying especially to their personal interests, prior knowledge and the requirements that in their view are posed by different courses. For example, for courses in Statistics, students with this learning style often use an analytic 
processing strategy in which they practise a lot of problems. For other courses they often employ a relating and structuring strategy. Monitoring processes in this learning style are mainly focused on the degree to which students understand the subject matter. When these students encounter difficulties, they often extensively diagnose why these have occurred. They try to find out why they do not understand something and then derive conclusions, for example, that they should upgrade their prior knowledge or that they should go back to previous learning units of chapters. Their adjustment strategy mostly consists of using other processing activities. For example, they consult other books or articles, they try to write down the difficult parts in schematic or strongly abbreviated form, or they try to sift out a particular part very detailedly and analytically. To test and evaluate their learning progress these students ask questions when they read, they try to explain the subject matter to an imaginary person, or they formulate in their own words or thoughts what a theory means. When they have thus constructed relationships, and when they can easily discern the main features in their own words, then they feel that they have mastered the subject matter.

S: "I always ask myself things when I read. When I ask those questions, I expect that somewhere the answers will come. Then you go on reading and if the answers do not come, you know there must be something wrong. (...) If you can create the problem yourself and invent another example, you have it under control."

I: "What do you do with difficult parts?"

S: "When I encounter something I have trouble with, I try to analyze why it is difficult. And then I have to draw conclusions. When, for example, I come to the conclusion that something is very difficult for me because I miss the prior knowledge, I must conclude I have to go back to that prior knowledge." (18, OU, TS)

Affective processes. Intrinsic interest in subject matter plays an important role in the regulation of the learning processes of these students. They can build many more relations between all kinds of topics and they read much more around the course content with subject matter that interests them. They are more inclined to learn by heart those topics that interest them less, and then they only read the course content. Generally, they experience a lot of pleasure in their studies and they find the courses enriching and interesting.

$S$ : "At this moment I have to do courses for my work, criminal law, tax laws and the like, and they don't interest me at all. I learn them in a totally different manner, that is constantly learning by heart. But in this OU-course I really want to get insight, so I study it in a completely different way. Not because I have to know it, but because I want to know it. These things fascinate me. When I learn about the way a plant grows, I think: how for heaven's sake is that possible?" $(3, \mathrm{OU}, \mathrm{NS})$ 
Mental models of learning. Students with this learning style view studying as a dialogue with people who know a lot, as being confronted with thoughts of others and thinking and forming an opinion about them. In their view studying is dealing with the subject matter in such a way that they can make relations to other courses, that they can follow a line of reasoning and that they can think further on that line. As study goals these students see the acquisition of insight, being able to derive formulas oneself, developing scientific thinking ability, being able to build relations, and becoming acquainted with the lines of thought in their subject area. In their view teachers should talk about things that are not in the books, be open to questions from students and their view on course topics, give students space to think along, and give their own opinions about subject matter. These students see as functions of tutorials, among other things, holding discussions and exchanging opinions and views. As further characteristics of good education they mention that it is not only directed at examinations but that it puts the development and interests of students to the fore.

Students with this learning style see it as their own responsibility to perform most learning functions. Learning, in their view, cannot be done for them by someone else. In the cognitive area they consider as important personal tasks, among other things, to try to think critically about the subject matter, develop a certain view on it, feed the content of learning units or chapters back to earlier learning units, and summarize their essence. They dislike studying for the sake of only being able to reproduce knowledge in an exam and forget it afterwards. In terms of the affective area, they see their own tasks as, among other things, being motivated, being interested in the subject matter, being involved in their studying and putting energy into it. As regulative tasks for themselves they see, for example, the asking of questions, being actively engaged with the subject matter, and reading books and magazines about the course topics. They are of the opinion that they should be realistic in diagnosing the causes of difficulties they experience and should find out where they should blame themselves and where there are didactic shortcomings. They think they should keep their eyes on the meaning of theories, instead of hurrying after points and gathering grades.

\section{I: "What do you consider tasks of a student in good education?"}

S: "Having motivation, you have to like it. Also being actively engaged in it. Putting energy into it, for example, not taking in everything, but also trying to think critically about things, trying to make the subject matter alive for yourself. (...) The most important thing of studying for me is to deal with the subject matter in such a way that it gets a part of yourself, that you can do something with it. That you can play with it, that you can relate it to other courses or daily live or whatever." (31, RU, PS) 
Learning orientations. Students with this learning style often study to deepen their interests, to develop as a person, or for the sake of studying itself that is found pleasant. Personal interest in the topics that are dealt with is often the motive for doing their studies. These students study to develop and enrich themselves as a person. They want to get acquainted with the subject area, are curious about it and want to know everything they can understand. They like to sharpen their thoughts with the ideas of others. They find it fascinating to follow the ideas of others, think about them and develop other versions of them.

S: "The most important reason for me to start these studies is that I have always been very interested in Natural sciences. (...) The most important thing of studying is that you are engaged with yourself, that you try to make yourself sharp, and especially to stay that way. I do not study for a career, but really only because I want to develop myself." (3, OU, NS)

\section{Application directed learning style}

Cognitive processing. In this learning style the usefulness of learning content for realizing personal goals is the most important criterion for selecting main points. Students mainly pay attention to those parts of the subject matter that have practical relevance. Phenomena from daily life, events they see on $\mathrm{TV}$, or read about in the newspapers, are considered more important than others. The processing strategy of this learning style is typically that students frequently search for relations between the subject matter and the reality to which it refers. Students try to concretize the subject matter; they use things they know from own experience, practical knowledge from their work, or events with which they are confronted daily via the media, as examples or visual images of what they read in their study materials. These students also try to apply in practice what they learn from a course. They use knowledge acquired through their studies to interpret and think about phenomena in their field that they know about via the media. They recognize phenomena in daily life from what they hear about in lectures or read about in their textbooks. They bring the subject matter to practice, in their work, or social, or free time, activities. These students feel a need to fill abstract lines of reasoning with concrete things and as long as they can imagine enough with the subject matter, they can follow it quite well. However, when this is no longer possible, they experience problems.

I: "Are there parts in the courses that you find more important than other parts?"

S: "The practical things are often much more important for yourself. The things you hear when you listen to the debates in the parliament, the things from daily life. (...) If you read in the newspaper that a minister is in trouble, then you already think: what would happen with this and that when a member of 
parliament proposes to change that law? Then you bring your knowledge into practice." (13, OU, LS).

Regulation of learning. This learning style is regulated both internally and externally. The more it is regulated internally, the less use students make of provided didactic aids. Their monitoring processes are mainly directed at the degree to which they can imagine the subject matter concretely and are able to apply it. Sometimes these students experience problems when the abstraction level of a course is too high. When these students encounter difficult parts, they employ a variety of adjustment activities. They consult other books, make comparisons, draw conclusions, make schemes with arrows, or resort to an analytic strategy. To test whether they have mastered the subject matter, students think of questions, assignments, problems and examples. They also try, for example, to envision chemical processes and describe that image in their own words. They find that they master the subject matter when they understand the relation between theory and practice, when they understand why, in the study materials, a certain theory is treated and afterwards a part of reality is explained.

\section{I: "What do you do with the assignments inserted into the learning units?"}

S: "I do have time to read and understand the learning units, but unfortunately I do not have time to do the assignments. Otherwise I do not read newspapers any more. (...) There are things that I find extremely important. That does not mean that the professor who sets the exam also considers them important. Sometimes I read something and I think: this is very important, I will have to remember it. But in the exam it does not come. That remains a problem for me, because for me everything is new. For someone from the Netherlands who has a lot of experience with democracy, these are very ordinary matters. But I learned to know democracy here. When I see the word democracy in a text, or constitutional state, or basic rights, I consider it extremely important for me to know about when I go back to my country." (19, OU, LS, political refugee)

When this learning style is regulated more externally, students make more use of the didactic aids. The concretizing and applying activities are then mainly activated by, especially, the assignments that are inserted into the course materials or provided by the teachers. These assignments stimulate them to give their own interpretations, to apply the subject matter, and to involve supplementary literature, newspapers, TV-programs and the like. Students adapt their approach to the learning objectives. They learn purposively and in general do what is recommended in the lectures and didactic aids.

Affective processes. Practical interest plays an important role in the regulation of the learning processes of these students. They automatically relate what fascinates them to daily life as in, for example, articles in the newspapers they read. They do nothing with topics that do not interest them. They study 
practically relevant parts more intensively; they have more trouble concentrating on abstract topics. They study a chapter more easily in which they encounter things that they are daily confronted with than chapters in which this is not the case. They remember fine details as a matter of course, because of their interest in them, without actually learning them.

S: "You study the interesting things more intensively and easily. You like them, and then you are more curious to go on. In contrast, when it is about abstract things I read for a quarter of an hour and then I find myself staring at the ceiling. Then I think: come on, another time. And then I go on for ten lines." (13, OU, LS)

Mental models of learning. Students with this learning style see as main goal of their studies learning to use the knowledge they acquire. They want to try to practically utilize the experiences they gain during their studies and they consider the usefulness of the subject matter to be very important. For example, they describe 'studying' as processing new information and being able to apply it in practice. For these students knowledge is only present if it can be used. They want concrete oriented education and dislike education that is abstract. They feel they must have the opportunity to be practically engaged with the subject matter. They consider it very important that the subject matter does not remain theoretical, but that it is applied by the teachers or course writers. Other valued expectations are that teachers should, among other things, stimulate students to think themselves, generate curiosity, be enthusiastic, and go beyond the boundaries of what is strictly necessary. In tutorials they like to focus on the things they find important and ask more specific questions about them.

As an important learning activity these students consider applying the subject matter in practice. They find it important to see what happens in their own environment and to compare that to what they have learned and done in their studies. They think that students should, from the very beginning, keep their vision directed at practice, because after their studies they also have to do that and because it makes their studies more useful. These students see as their own tasks, among other things, the invention of practical applications, showing interest by asking a lot of questions and talking to other people about the course topics, and trying to do something with the subject matter.

I: "What do you actually mean by learning and studying?"

$S$ : "Acquiring new information, processing it, comparing it to what I already know and being able to apply it in practice. I do not mean becoming a psychologist immediately, but also being able to apply the things I have learned in my daily contact with people, situations and work. Not by attaching certain labels, but through gaining a broader view at the world. (27, RU, PS) 
Learning orientations. The learning orientation in this learning style is often intrinsically vocationally oriented. Students want to acquire knowledge and skills to be able to use in their current or future work. Or they want to use the content of their studies in their daily functioning, for example, in their social and societal activities. They want to learn a profession, acquire professional skills. They think they need the knowledge to be able to realize their personal goals later on. These students see as goals of studying, among other things: getting a job, being able to practice a profession, and applying the knowledge acquired through their studies.

I: "What do you try to gain from your studies?"

S: "You try to apply it in practice. I think you get knowledge by studying, and of course it is very useful that you can also apply these things when you find a job in the future. Maybe also just applying them in practice for yourself, so looking around in your own environment what happens there, and comparing that to what you have learned and done." (32, RU, PS)

\section{Conclusions and discussion}

The most important conclusion of these qualitative studies is that there are big differences among students in the way they carry out the various learning functions in their normal studies. These differences also exist among students who get the same instruction. Students differ in the thinking activities they employ in order to learn. Some students experience difficulty in carrying out almost all learning functions, others perform only some functions themselves, and some carry out more functions. Metacognition, in the sense of both regulation strategies and mental models of leaming, plays a central role in regulating student learning in higher education.

The manner in which students carry out learning functions is associated with internal and external sources. Internal sources mainly concern students' mental models of learning, learning orientations and skill in the use of learning activities. All students consider it important that almost all learning functions be carried out, but they differ in their views on the question of who is responsible for doing so; they themselves, or instruction. It is remarkable that the learning functions that are not carried out by students are often perceived by them to be not their responsibility, but as the tasks of instruction. Mental models of learning and learning orientations influence the way students interpret, appraise and use instructional measures. The effect of external regulation devices, such as questions, assignments, learning objectives and the like, is dependent on the interpretations and appraisals students give to them. The way students interpret instructional measures seems mainly to be dependent on their mental models of learning, and the way in which they appraise 
those measures to be based on their learning orientations. External sources that influence the way students perform learning functions mainly concern the instructional strategies according to which didactic measures are shaped. When a function is substituted (carried out) by instruction, it is often not carried out by students. When a function is activated in students by instruction, its fulfilment is dependent on the students' mental model of learning and learning orientation. When instruction does not address a certain learning function, its execution becomes dependent on the learning style of students.

These differences among students can be grouped into four main categories that represent qualitatively different learning styles. A psychological coherence seems to exist between the employment of learning activities and the nature of mental learning models and learning orientations. These styles of learning differ from each other in five areas: the strategies students use to process learning contents, the strategies they use to regulate their learning, the affective processes that occur during studying, and the mental models of learning and learning orientations of students. These styles were referred to as an undirected, a reproduction directed, a meaning directed and an application directed learning style. These are summarized in Table 2 . The three last mentioned styles may vary from externally to internally regulated. Of the seven identified learning style variants, there are only two in which the didactic measures result in a more constructive way of learning than that which students would adopt on their own accord, namely both externally regulated variants of the meaning and application directed learning styles.

There often seems to be a development within a learning style from external to internal regulation. Thus, students with a reproduction directed learning style often refer to secondary education as an explanation for their way of learning. The more experience and skill students get with a certain learning style, the more it is executed under internal control (compare Schmeck \& Geisler-Brenstein, 1989). They continue to adopt this style until they experience friction between it and the demands of, for example, higher education, or until they get dissatisfied with it for another reason. Only then do they begin to adopt an alternative style under external regulation. In this way an internally regulated reproduction directed learning style can change into an extemally regulated meaning directed style.

Mental models of learning seem mainly to be based on experiences acquired in formal educational situations, and much less so on learning experiences acquired outside education. Adult students who for a long time have followed no formal education, especially interpret the demands of their studies from the mental model of learning they formed many years ago. They seem to have stored all intermediate learning experiences they acquired outside formal education in a knowledge domain that is not connected, according to them, 
Table 2. Learning styles and their components

\begin{tabular}{|c|c|c|c|c|}
\hline \multirow[t]{2}{*}{ Components } & \multicolumn{4}{|l|}{ Learning styles } \\
\hline & Undirected & $\begin{array}{l}\text { Reproduction } \\
\text { directed }\end{array}$ & $\begin{array}{l}\text { Meaning } \\
\text { directed }\end{array}$ & $\begin{array}{l}\text { Application } \\
\text { directed }\end{array}$ \\
\hline $\begin{array}{l}\text { Cognitive } \\
\text { processing }\end{array}$ & $\begin{array}{l}\text { Hardly any } \\
\text { processing }\end{array}$ & $\begin{array}{l}\text { Stepwise } \\
\text { processing }\end{array}$ & $\begin{array}{l}\text { Deep } \\
\text { processing }\end{array}$ & $\begin{array}{l}\text { Concrete } \\
\text { processing }\end{array}$ \\
\hline $\begin{array}{l}\text { Regulation of } \\
\text { learning }\end{array}$ & $\begin{array}{l}\text { Lack of } \\
\text { regulation }\end{array}$ & $\begin{array}{l}\text { Mostly external } \\
\text { regulation }\end{array}$ & $\begin{array}{l}\text { Mostly self- } \\
\text { regulation }\end{array}$ & $\begin{array}{l}\text { Both external } \\
\text { and self- } \\
\text { regulation }\end{array}$ \\
\hline $\begin{array}{l}\text { Affective } \\
\text { processes }\end{array}$ & $\begin{array}{l}\text { Low-self-esteem } \\
\text { Failure } \\
\text { expectations }\end{array}$ & $\begin{array}{l}\text { Fear of } \\
\text { forgetting }\end{array}$ & $\begin{array}{l}\text { Intrinsic } \\
\text { interest }\end{array}$ & $\begin{array}{l}\text { Practical } \\
\text { interest }\end{array}$ \\
\hline $\begin{array}{l}\text { Mental model } \\
\text { of learning }\end{array}$ & $\begin{array}{l}\text { Cooperation and } \\
\text { being stimulated }\end{array}$ & $\begin{array}{l}\text { Intake of } \\
\text { knowledge }\end{array}$ & $\begin{array}{l}\text { Construction of } \\
\text { knowledge }\end{array}$ & $\begin{array}{l}\text { Use of } \\
\text { knowledge }\end{array}$ \\
\hline $\begin{array}{l}\text { Learning } \\
\text { orientation }\end{array}$ & Ambivalent & $\begin{array}{l}\text { Certificate and } \\
\text { self-test } \\
\text { oriented }\end{array}$ & $\begin{array}{l}\text { Person } \\
\text { oriented }\end{array}$ & $\begin{array}{l}\text { Vocation } \\
\text { oriented }\end{array}$ \\
\hline
\end{tabular}

to an experience of 'learning in an educational environment'. Although, for example, they may have studied all kind of work-related documents in a 'deep' way, the mere testing of learning achievements that is inherent to educational situations is reason enough for them to activate the mental learning model of 'learning in educational settings'. This often results in a regression to a reproduction directed learning style, that they were used to adopt in former days.

The results indicate that systematic differences exist among students in the way they carry out learning functions. To optimize the quality of learning processes it is important that all functions are performed. For instructional design this means that functions should be substituted or activated other than those that students perform on their own accord. A good diagnosis of the learning styles of students is indispensable for this.

In conclusion, the results of these studies point to the importance of discouraging undirected and reproduction directed learning styles of students, and encouraging meaning and application directed learning styles. These last 
mentioned styles appear to be the most consistent with the goals of higher education. Higher education especially aims to educate people who should be able to think, decide and keep on learning independently. An educational conception based on the intake of existing, external knowledge, is not congruent with this aim, whereas a conception in which studying is seen as an active, self-directed and constructive process is. Process oriented instruction, in which the processes of knowledge construction and utilization and, therefore, the learning and thinking activities of students occupy a central place, seems to be a good way to improve the quality of learning processes in higher education (e.g. Vermunt, 1994). It is aimed at teaching domain-specific knowledge and thinking strategies that students need to construct, modify and utilize that knowledge in coherence. It is characterized by a gradual and systematic transfer of control over learning processes from instruction to learners. The most important task of teaching is no longer transmitting knowledge, but initiating, coaching and influencing the thinking processes that students use to learn. The results indicate that in order to bring about constructive and independent learning behaviour, instruction should be mainly aimed at developing self-regulated control strategies and mental learning models in students in which the construction and use of knowledge are central (compare Janssen, 1993). The learning processes of students should be more in focus of education, in order to achieve this. The habit of many teachers in higher education to speak to hundreds of students in order to transfer the learning contents to them, is probably based more on tradition than on learning psychological findings.

Sixteen principles have been identified for the design of process oriented instruction (see Vermunt, 1994). They are based on the results of psychological research in the last decennium on realizing effective learning processes. The principles can be divided in general principles, that are in operation during the entire teaching learning process, and specific principles, that are in operation during a certain phase and subsequently, are substituted for by other principles. General principles are, for example, focusing on learning and thinking activities, teaching of thinking strategies situated in a subject domain, gradual transfer of control, developing students' mental model of learning, taking the learning orientation into account, and promoting transfer of learning and thinking strategies. Specific principles can be divided into three phases of the teaching learning process. In the first phase the thinking strategies and domain-specific conceptions of students are diagnosed, and instruction is adapted to their learning styles and preconceptions (see also Meyer, 1993). In the second phase cognitive, affective and regulative learning and thinking activities are taught in coherence. Usually covert learning and thinking activities are modelled as overtly and explicitly as possible. Next, 
students are activated to use the modelled learning and thinking activities themselves in different situations, and they get process oriented feedback on the quality of the way they did it (compare Lonka, 1993). Gradually also this activation is withdrawn and, by creating challenging learning environments, a continuous capitalizing on the use of the newly acquired learning and thinking skills by students is realized. The third phase is the testing phase. In this phase tests are administered that measure thinking activities and conceptions of the subject matter. Essentially this phase is identical to the diagnostic phase in the beginning. From the difference between these two diagnostic moments it turns out to what extent thinking skills have improved and conceptions of the subject domain have changed. Process oriented instruction may be applied in various learning environments, for example, in lectures, co-operative learning, study materials, and the design of computer supported or multi-media learning environments.

There is clearly a need to verify the conclusions of the small scale qualitative studies reported here. Future research should also be directed at establishing the way in which the transfer from external to internal regulation of learning processes can be concretely realized in various learning environments. Important questions in this respect are, for example, how different levels of internal and external regulation act upon each other, whether this occurs differently in various types of learning environments and what the effects of different learning environments on the thinking strategies people use to learn are. More research is certainly needed on the interplay between external and internal regulation of learning processes.

\section{Acknowledgement}

The author wishes to thank Piet Janssen and Erik Meyer for their valuable comments on an earlier draft of this article.

\section{References}

Brown, A.L. (1987). 'Metacognition, executive control, self-regulation and other more mysterious mechanisms'. In F.E. Weinert \& R.H. Kluwe (Eds.), Metacognition, motivation and understanding (pp. 65-116). Hillsdale, NJ: Erlbaum.

Entwistle, N.J., \& Ramsden, P. (1983). Understanding student learning. London: Croom Helm. Flavell, J.H. (1987). 'Speculations about the nature and development of metacognition'. In F.E. Weinert \& R.H. Kluwe (Eds.), Metacognition, motivation and understanding (pp. 21-29). Hillsdale, NJ: Erlbaum.

Gibbs, G., Morgan, A., \& Taylor, E. (1984). 'The world of the learner'. In F. Marton, D. Hounsell \& N. Entwistle (Eds.), The experience of learning (pp. 165-188). Edinburgh: Scottish Academic Press. 
Janssen, P.J. (1993, July). An analytic framework to describe the experiences of both students and lecturers. Paper presented at the III European Congress of Psychology, Tampere, Finland.

Lonka, K. (1993, September). Activating instruction - How to foster study and thinking skills in higher education. Paper presented at the 5th Conference of the European Association for Research on Learning and Instruction, Aix-en-Provence, France.

Marton, F. (1986). 'Phenomenography - A research approach to investigating different understandings of reality'. Journal of Thought, 21, 28-49.

Marton, F. (1990). 'The phenomenography of learning - a qualitative approach to educational research and some of its implications for didactics'. In H. Mandl, E. De Corte, S.N. Bennett \& H.F. Friedrich (Eds.), Learning and Instruction - European research in an international context. Volume 2.1 (pp. 601-616). Oxford: Pergamon Press.

Marton, F., Dall'Alba, G., \& Beaty, E. (1993). 'Conceptions of learning'. International Journal of Educational Research, 19, 277-300.

Meyer, E. (1993, September). The individual difference modelling of student learning. Paper presented at the 5th Conference of the European Association for Research on Learning and Instruction, Aix-en-Provence, France.

Moran, A. (1991). 'What can learning styles research learn from cognitive psychology?' Educational Psychology, 11, 239-245.

Murphy, K.L. (1990, April). Patronage and an oral tradition: influences on attributions of distance learners in a traditional society. Paper presented at the Annual Meeting of the American Educational Research Association, Boston, MA.

Pramling, I. (1990). Learning to learn: a study of Swedish preschool children. New York: Springer.

Prosser, M., Trigwell, K., \& Taylor, P. (1994). 'A phenomenographic study of academics' conceptions of science learning and teaching'. Learning and Instruction, 4, 217-231.

Säljö, R. (1988). 'Learning in educational settings: methods of inquiry'. In P. Ramsden (Ed.), Improving learning: new perspectives (pp. 32-48). London: Kogan Page.

Schmeck, R.R. (1983). 'Learning styles of college students'. In R. Dillon \& R.R. Schmeck (Eds.), Individual differences in cognition, I (pp. 233-279). New York: Academic Press.

Schmeck, R.R., \& Geisler-Brenstein, E. (1989). 'Individual differences that affect the way students approach learning'. Learning and Individual Differences, 1, 85-124.

Short, E.J., \& Weisberg-Benchell, J.A. (1989). 'The triple alliance for learning: cognition, metacognition, and motivation'. In C.B. McCormick, G.E. Miller \& M. Pressley (Eds.), Cognitive strategy research: from basic research to educational applications (pp. 33-63). New York: Springer.

Shuell, T.J. (1988). 'The role of the student in learning from instruction'. Contemporary Educational Psychology, 13, 276-295.

Vermunt, J.D. (1989, September). The interplay between internal and external regulation of learning, and the design of process-oriented instruction. Paper presented at the Third Conference of the European Association for Research on Learning and Instruction, Madrid, Spain.

Vermunt, J.D. (1992). Leerstijlen en sturen van leerprocessen in het hoger onderwijs - Naar procesgerichte instructie in zelfstandig denken. [Learning styles and regulation of learning in higher education - Towards process-oriented instruction in autonomous thinking]. Amsterdam/Lisse: Swets \& Zeitlinger.

Vermunt, J.D. (1994). 'Design principles of process-oriented instruction'. In F.P.C.M. de Jong \& B.H.A.M. Van Hout Wolters (Eds.), Process-oriented instruction and learning from text (pp. 15-26) Amsterdam: VU University Press.

Volet, S.E. (1990). 'Goals in the adaptive learning of university students'. In H. Mandl, E. de Corte, S.N. Bennett \& H.F. Friedrich (Eds.), Learming and instruction - European research in an international context. Volume 2.1 (pp. 497-516). Oxford: Pergamon Press. 